Atmos. Chem. Phys., 2, 1-16, 2002

www.atmos-chem-phys.org/acp/2/1/

\title{
Nucleation events in the continental boundary layer: Influence of physical and meteorological parameters
}

\author{
M. Boy and M. Kulmala \\ Dept. of Physics, University of Helsinki, P.O. Box 64, FIN-00014, UHEL, Finland \\ Received: 3 July 2001 - Published in Atmos. Chem. Phys. Discuss.: 8 October 2001 \\ Revised: 18 December 2001 - Accepted: 19 December 2001 - Published: 10 January 2002
}

\begin{abstract}
The relationship between nucleation events and numerous physical and meteorological parameters was analysed using data collected at the Station for Measuring Forest Ecosystem-Atmosphere Relations (SMEAR II) in Hyytiälä, Finland. To do this, measurements of solar radiation (ultraviolet [UV], global, photosynthetically active radiation [PAR], net, reflected global radiation and reflected PAR), gas concentrations, temperature, humidity, wind direction, horizontal and vertical wind speed, horizontal and vertical wind standard deviations and particle concentrations were collected over a 4 year period. For the year 1999 a detailed analysis of data were completed by examining parameters in order to determine the physical and meteorological conditions favourable to the formation of new particles. A comparison of different wavelength bands during the bursts of new particles led to the suggestion, that UV-A solar radiation seems to be the most probable radiation band concerning the photochemical reactions involved in the production of condensable vapours. Furthermore a high correlation between the daily curves of UV-A irradiance and the concentration of 3-5 nm particles was found throughout the year and examples will be given for two days. During the whole year the concentration of $\mathrm{H}_{2} \mathrm{O}$ is very low at times nucleation occurs compared to the average of the corresponding month. Especially in June and July many nonevent days with high solar irradiance show high amounts of water molecules. To combine these results a "nucleation parameter" was calculated for the year 1999, by dividing UV-A solar radiation by the concentration of $\mathrm{H}_{2} \mathrm{O}$ and temperature. Throughout the year nearly all nucleation event days reach a value of the "nucleation parameter" of at least $5.4 \times 10^{-25} \mathrm{~W}$ m molecules ${ }^{-1} \mathrm{~K}^{-1}$. Non-event days with high values $\left(>2.7 \times 10^{-25} \mathrm{~W}\right.$ m molecules $\left.{ }^{-1} \mathrm{~K}^{-1}\right)$ are mostly accompanied by high concentrations of existing particles.
\end{abstract}

Correspondence to: M. Boy (Michael.Boy@helsinki.fi)

\section{Introduction}

Nucleation, or the formation of new aerosol particles, detected at sizes greater than $3 \mathrm{~nm}$, and their subsequent growth to $\sim 100 \mathrm{~nm}$ in $1-2$ days, has in recent years been frequently observed in the continental boundary layer in several European locations. The observations span from Northern subarctic Lapland, over the remote boreal forest (Mäkelä et al., 1997; Kulmala et al., 1998) and suburban Helsinki (Väkevä et al., 2000), to industrialised agricultural regions in Germany (Birmilli and Wiedensohler, 1998).

Atmospheric nucleation can occur by binary nucleation of $\mathrm{H}_{2} \mathrm{SO}_{4}$ and $\mathrm{H}_{2} \mathrm{O}$ (Kulmala et al., 1998) or ternary nucleation of $\mathrm{H}_{2} \mathrm{O}, \mathrm{NH}_{3}$ and $\mathrm{H}_{2} \mathrm{SO}_{4}$ (Korhonen et al., 1999). According to Kulmala et al. (2000a) binary nucleation theory is not able to predict observed nucleation rates in the atmosphere at typical tropospheric sulphuric acid concentrations $\left(10^{5}-10^{7}\right.$ molecules $\mathrm{cm}^{-3}$, Weber et al., 1998 and 1999). Ternary nucleation, however, gives significantly higher nucleation rates and thus can better predict the formation of new particles at typical tropospheric conditions (ammonia level of a few ppt). Kulmala et al. (2000a) suggest that nucleation occurs almost everywhere in the atmosphere, at least during the daytime and leads to a reservoir of thermodynamically stable clusters (TSCs), which under certain conditions grow to detectable sizes.

Solar UV-radiation indirectly controls the appearance of newly formed particles and their growth, as it is the driving force behind photochemical reactions. Pirjola (1999), using an aerosol dynamic model which included binary nucleation, calculated that a $30 \%$ increase in UV-B irradiation causes an increase of about $86 \%$ in the nucleated particle concentration. Solar radiation also enhances the turbulent kinetic energy and thereby the mixing of the boundary layer. Nilsson et al. (2001a) calculated that during the field measure- 

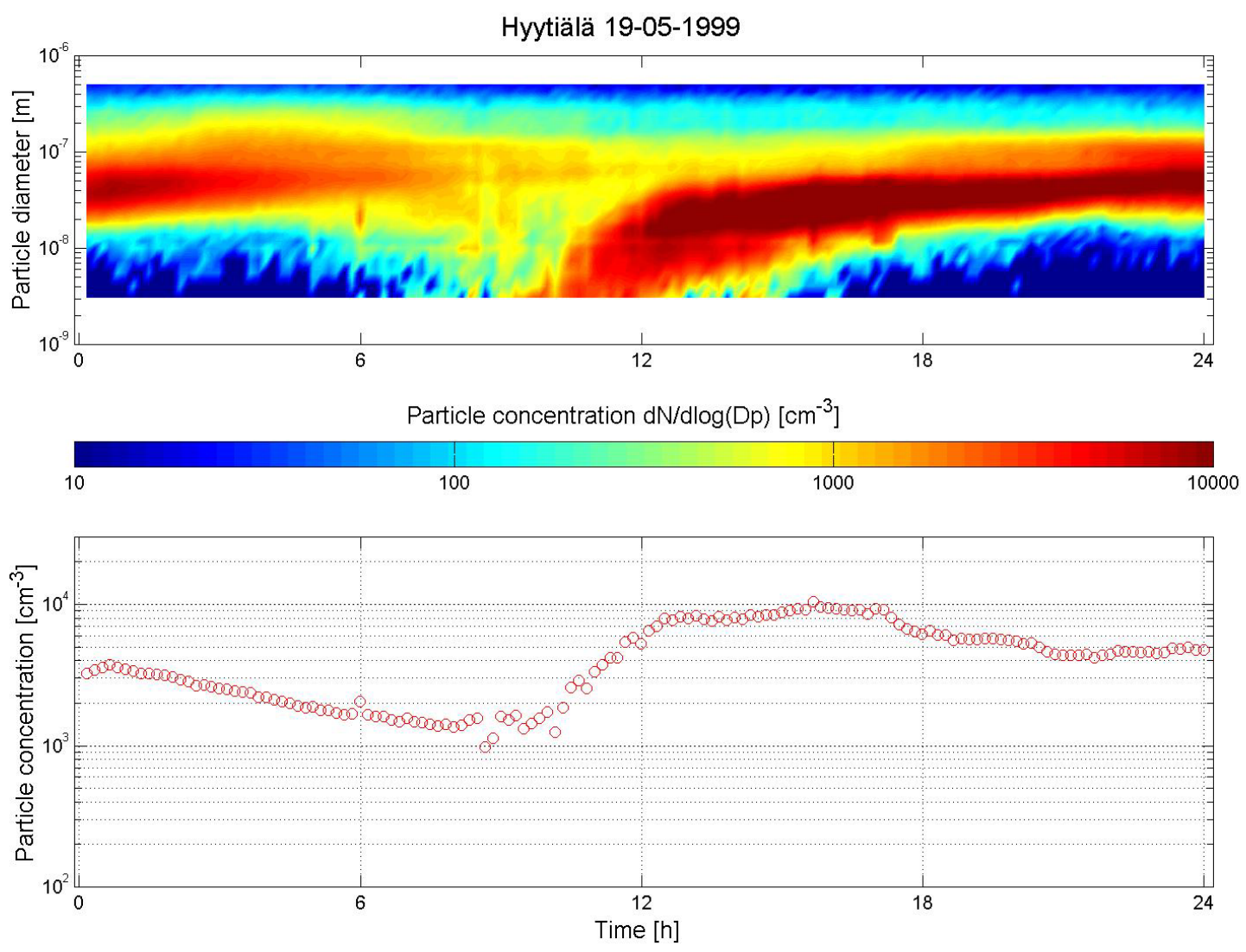

Fig. 1. Aerosol number size distribution from the DMPS system at $2 \mathrm{~m}$ height in Hyytiälä.

ment campaigns of the BIOFOR project (Biogenic Aerosol Formation in the Boreal Forest), a two times higher value of surface layer sensible heat flux took place on nucleation days than on days without nucleation (BIOFOR 1 from 11 April to 22 May in 1998, BIOFOR 2 from 17 July to 29 August in 1998 and BIOFOR 3 from 11 March to 30 April in 1999, Hyytiälä, Finland).

In 1999, seventy nucleation events were observed at the boreal forest site in Hyytiälä. Table 1 gives a summary of observed meteorological and physical parameters for all event cases. The dry aerosol number size distribution is shown as an example of a nucleation event for the 19th of May (Fig. 1). The detectable $3 \mathrm{~nm}$ particle concentrations increased by 1 to 3 orders of magnitude around 9 a.m. (Nucleation event start) and later decreased to their original levels by 3 p.m. (Nucleation event end). A new cluster needs time to grow to $3 \mathrm{~nm}$ in size. This time varies under different atmospheric situations, but because we do not know the exact growth time to $3 \mathrm{~nm}$ the start and the cut-off of the particle bursts will be used as nucleation start and nucleation end throughout this paper. The purpose of this paper is to analyse the meteorological and physical conditions necessary for such bursts to take place and in particular our aim is to find a general correlation that could be used to determine the prob- ability of newly formed particles to occur.

\section{Measurements}

Data were collected at the Station for Measuring Forest Ecosystem-Atmosphere Relations (SMEAR II) in Hyytiälä, Finland. The station is located in Southern Finland $\left(61^{\circ} 51^{\prime}\right.$ $\mathrm{N}, 24^{\circ} 17^{\prime} \mathrm{E}, 181 \mathrm{~m}$ asl), within extended areas of Pine dominated forests. For a detailed description of SMEAR II station and instrumentation, we refer to Vesala et al. (1998). The conditions at the site are typical for a background location, however, occasionally measurements were polluted by the station buildings $(0.5 \mathrm{~km})$ and the city of Tampere $(60 \mathrm{~km})$ both located in a west-south-west direction from the instruments.

Nucleation events have been classified into 3 groups (Mäkelä et al., 2000). Class A events are categorised by high amounts of $3 \mathrm{~nm}$ particles and continuous growth to larger particle sizes (Fig. 1). Class B events show the same behaviour with less clarity and class $\mathrm{C}$ events are marginal nucleation events where one of the two stages was not clearly observed. This type of classification is quite subjective and takes into account the uncertainties and limitations of the instrumentation. Because of this there will always exist an 
Table 1. Measured physical and meteorological parameters in Hyytiälä for the time the particle burst started. The monthly average values for the non-event days are calculated for January between 10 to 11 a.m., for October between 10 to 12 a.m. and for all other months between 9 to 11 a.m. (Finnish winter time); hor.Std. and ver.Std. are the standard deviations to the horizontal and vertical wind speed, respectively

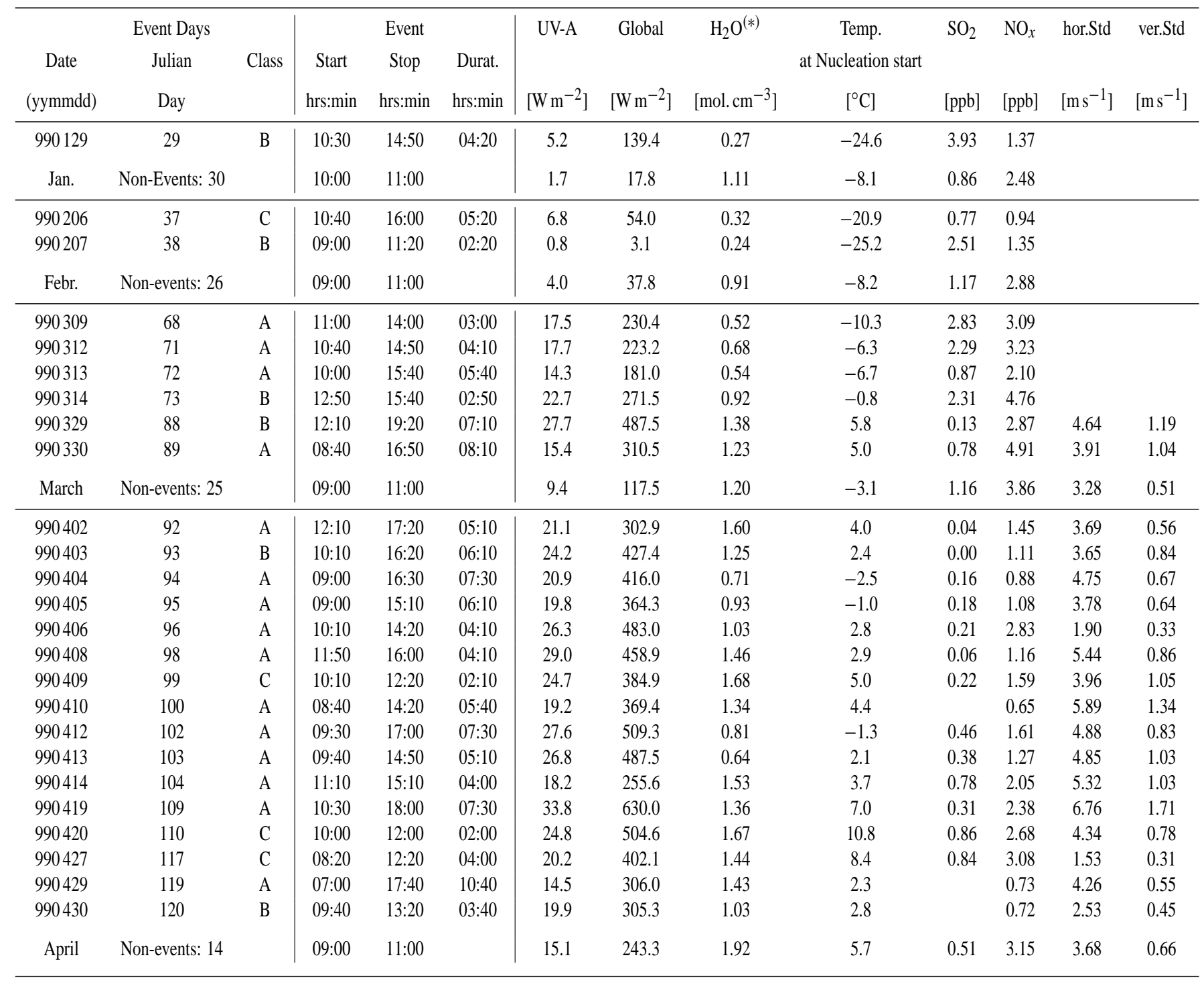

Table 1 continued ...

overlap between the classes. For class $\mathrm{C}$ events, many days have high numbers of newly formed particles while the continuous growth to larger particles is not detected. There are also "non-event days" which show similar profiles as class $\mathrm{C}$ event days, and viewing the data one finds cases where labelling of events is problematic. On some days the formation of new particles and their growth to larger particle sizes may have started for a short time but was than interrupted by changes in one or more parameters (e.g. intensity of solar radiation).
The incoming and outgoing radiation above the forest was measured over several wavelength bands: ultraviolet $\mathrm{A}$ and B (UV-A: 0.32-0.40 $\mu \mathrm{m}$; UV-B: 0.28-0.32 $\mu \mathrm{m})$, PAR $(0.4$ $0.7 \mu \mathrm{m})$, global radiation $(0.3-4.8 \mu \mathrm{m})$ and net radiation $(0.3-40 \mu \mathrm{m})$. The components of reflected radiation were measured for global and PAR radiation. Basic readings were taken at the top of a $15 \mathrm{~m}$ tall tower (above the forest). Reflected global radiation (albedo) and reflected PAR and net radiation measurements were taken from a $70 \mathrm{~m}$ mast.

Concentrations of $\mathrm{H}_{2} \mathrm{O}, \mathrm{NO}_{\mathrm{x}}$ and $\mathrm{SO}_{2}$ were measured with 
Table 1. Continued...

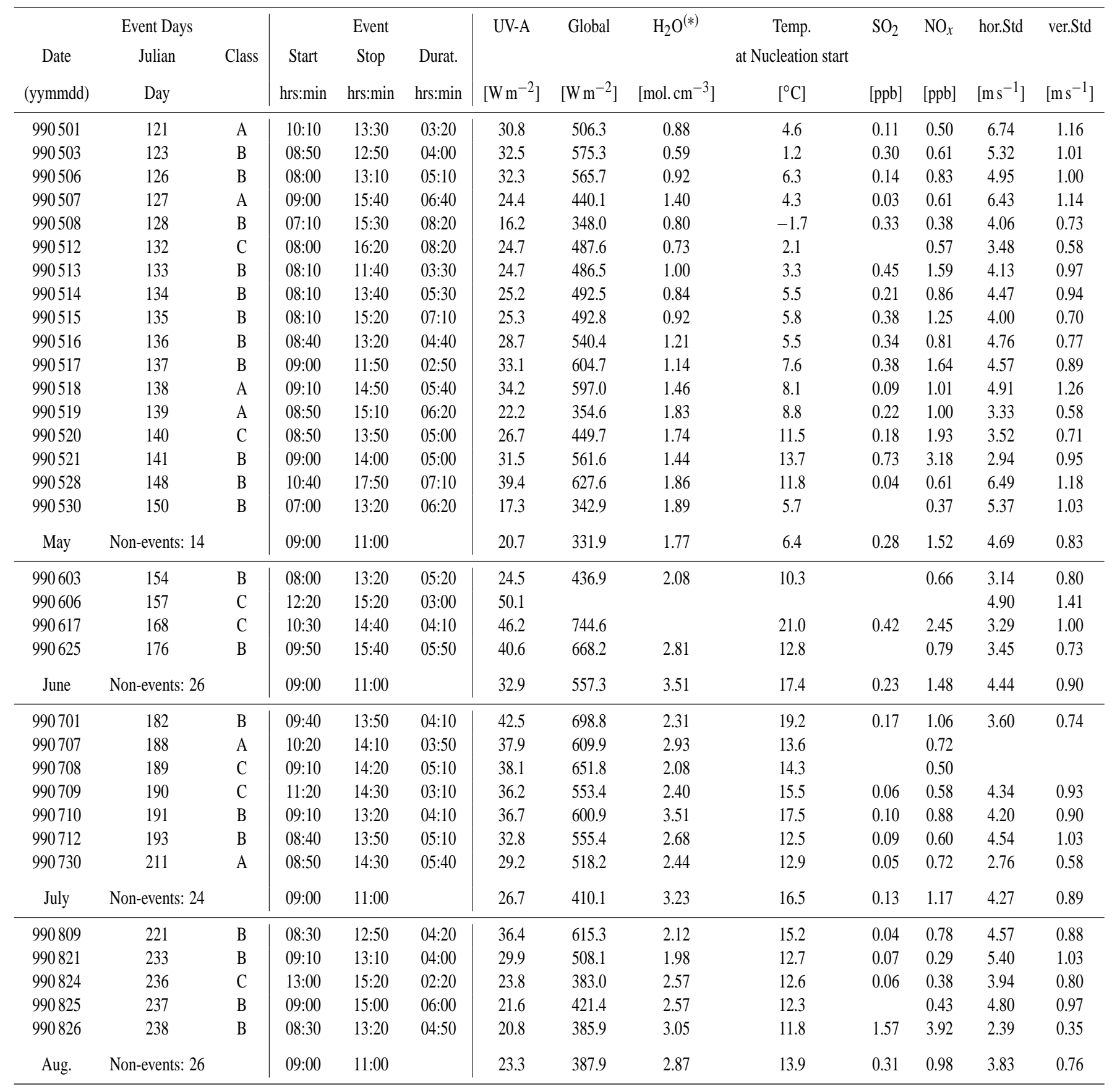

Table 1 continued ...

an infrared radiation gas analyzer, chemiluminescence gas analyzer and a fluorescence analyzer with an UV absorption analyzer. Air samples were collected from the mast at $4.2 \mathrm{~m}$, $16.8 \mathrm{~m}$ and $67.2 \mathrm{~m}$ height levels every 5 minutes. Temperature (measured with PT-100-sensors) and horizontal wind speed (measured with cup anemometers) were collected every $50 \mathrm{~s}$ at these three heights as well. Wind direction was measured every $50 \mathrm{~s}$ by wind vanes at $16.8 \mathrm{~m}$ and $50.4 \mathrm{~m}$ heights.

A Differential Mobility Particle Sizer (DMPS) system (lo- 

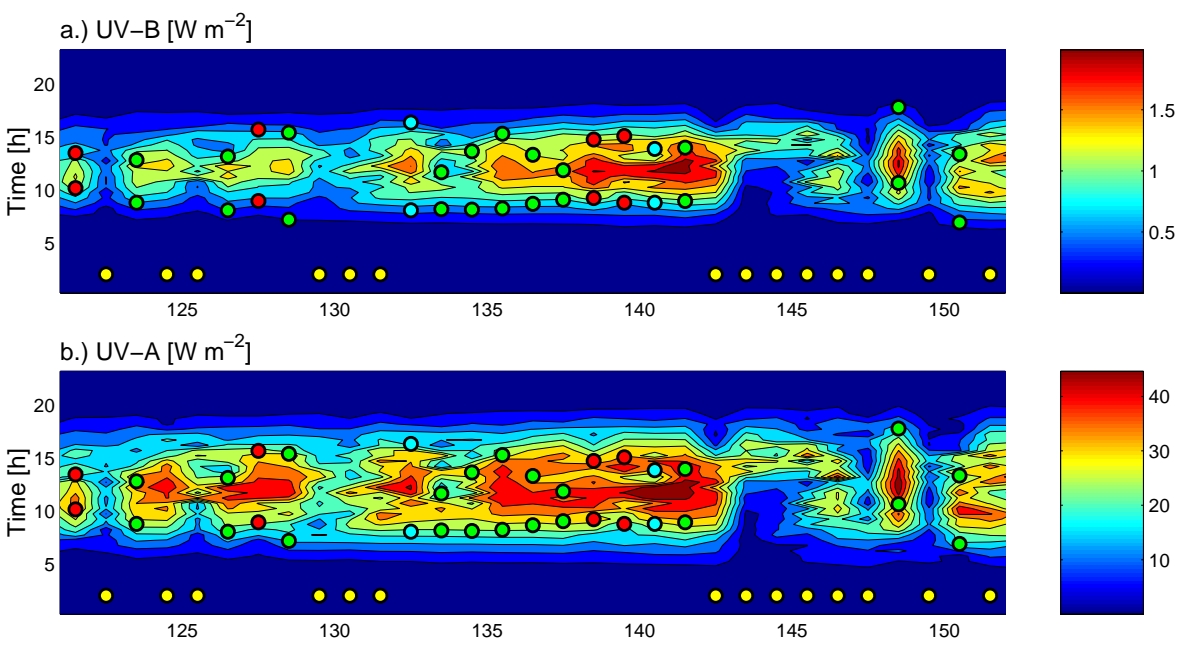

c.) Global $\left[W m^{-2}\right]$

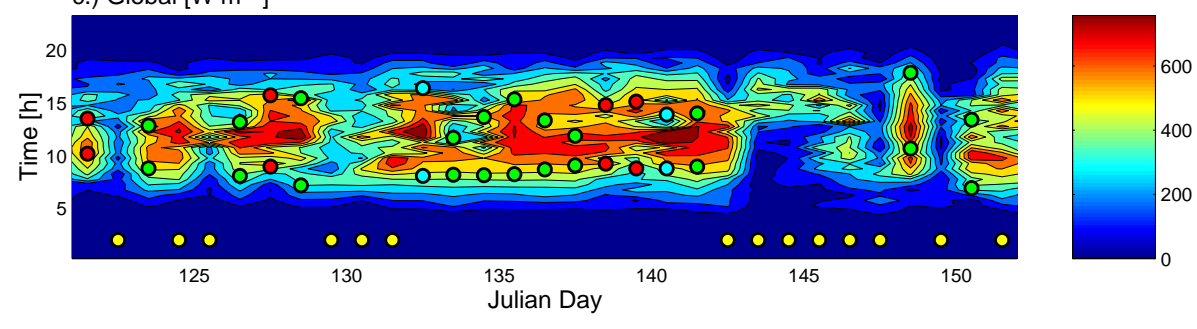

Fig. 2. Half-hour average values of solar irradiance during May 1999. The initiation and the cut-off of the smallest detectable particle bursts are marked with red, green and cyan labels for A-, B- and C-Events respectively; yellow labels are used for non-event days. cated near the mast) monitors aerosol size distributions at $2 \mathrm{~m}$ height from ground level giving a continuous view of the distribution and evolution of sub-micrometer aerosol particles. The DMPS system used here actually consists of two components. The first one includes a TSI 3025 UFCPC and a Hauke-type short DMA (Differential Mobility Analyzer) and measures particles between 3 and $20 \mathrm{~nm}$ in dry diameter. The second includes a TSI 3010 CPC and a Hauke-type medium DMA capable of measuring particles between 20 and $500 \mathrm{~nm}$. Particle size distribution is recorded every 10 minutes. A detailed description of this system is given in Mäkelä et al. (1997) and Jokinen and Mäkelä (1997).

A Sensitron AB monostatic $2.3 \mathrm{kHz}$ Doppler Sound Detection and Ranging system (SODAR) was used to measure the stability of the air (echo strength). The means and standard deviations of the horizontal and vertical wind components as well as wind direction up to $500 \mathrm{~m}$ height in $25 \mathrm{~m}$ intervals were calculated. Raw echo measurements were achieved in 8 -second cycles between three antennas. The vertical antenna echo strength was averaged and stored every 3 minutes. Average and standard deviations of wind speed were then derived and averaged over 30 minute period.

\section{Results and discussion}

Our following results give a detailed analysis of the different parameters and their correlation with the formation of new aerosols. In Sect. 3.8 we introduce a "nucleation parameter" using UV-A radiation, $\mathrm{H}_{2} \mathrm{O}$ concentration and temperature measurements.

\subsection{Radiation}

Nucleation, or the formation of $3 \mathrm{~nm}$ particles, occurs only on days with strongly increasing solar radiation. Figure 2 shows UV-A, UV-B and global solar radiation for May 1999, Julian day 121 to 151 respectively as half hour average values from $0.15 \mathrm{a} . \mathrm{m}$. to $11.15 \mathrm{p} . \mathrm{m}$. The beginning of the $3-5 \mathrm{~nm}$ particles bursts occurs throughout the year almost always in the morning when radiation reaches a value greater than one third of the daily maximum. Nucleation stops when the radiation decreases to approximately the same value. The appearance of small clouds for a short time stopped the formation of new particles on some event days (e.g. Julian day 137) and on some other event days the formation continued after the clouds disappeared (e.g. Julian day 139). The amount of solar radiation necessary to start the formation of new particles differs throughout the year depending on different parameters. However, on event days the curves of the different radiation bands are far above the curves of non-event days. In May UV-A and UV-B radiation show a diurnal, sinusoidal profile with a peak value of 39.5 or $1.54 \mathrm{~W} \mathrm{~m}^{-2}$ on days with nucleation and 24.9 or $0.92 \mathrm{~W} \mathrm{~m}^{-2}$ on days without, i.e. a $59 \%$ and $67 \%$ higher values in UV-A and UV-B radiation on nucleation days, respectively. For global radiation the values are $665.8 \mathrm{~W} \mathrm{~m}^{-2}$ for days with nucleation and $382.4 \mathrm{~W} \mathrm{~m}^{-2}$ for days without nucleation, an increase of $74 \%$. Birmilli and 

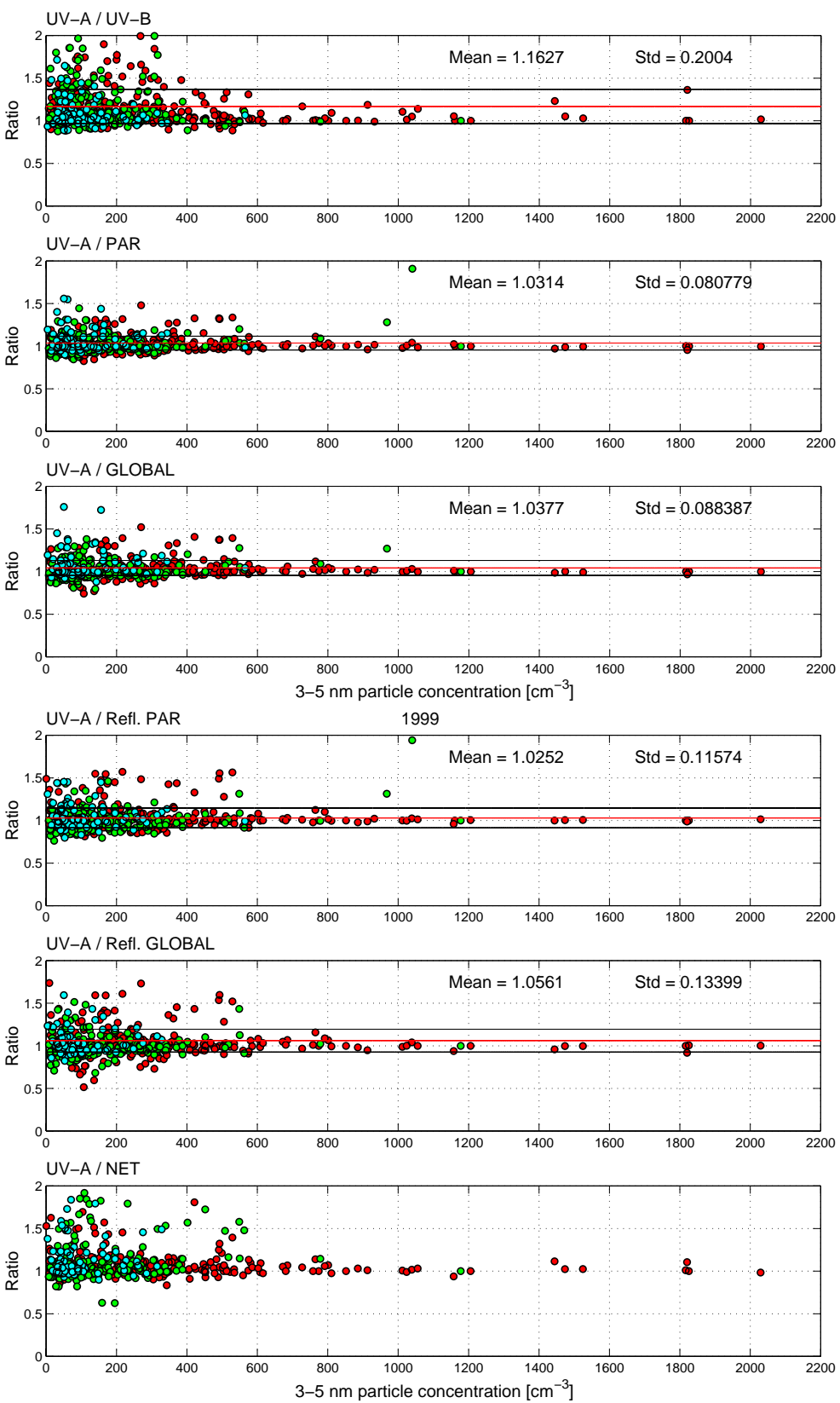

Fig. 3. Half-hour average ratios of UVA to different wavelength bands against the number concentration of the $3-5 \mathrm{~nm}$ particles for the time particle bursts being observed. All radiation intensities have been normalised by their daily maximum values. A-, B- and C-Events marked with red, green and cyan labels respectively.
Wiedensohler (2000) recorded an approximately 50\% higher solar radiation flux on event days than on non-event days during a comprehensive atmospheric experiment period in Melpitz, $50 \mathrm{~km}$ NE of Leipzig, Germany between 26 March 1996 and 15 August 1997.

It is still an open question if there is an influence of certain wavelengths of the solar spectra on the formation of new aerosols. Analysis of the data of 1999 shows, that UV-A has a higher correlation with nucleation than any other wavelength band. We found that UV-A values divided by their daily maxima are higher during nucleation events than the similarly normalized values of other wavelength bands (UV-B, global,
PAR, net or reflected PAR, and reflected global solar irradiance). Figure 3 show the ratios of these values against the concentration of 3-5 nm particles. The calculated mean values of the ratios are always above unity with standard deviations between 0.08 and 0.2 (included in all graphs of Fig. 3 except the graph of ratio UV-A / net). The calculated mean values of the reciprocal of the ratios are always smaller than unity (exact values UV-B/UV-A: 0.899, PAR/UV-A: 0.981, global/UV-A: 0.977, reflected PAR/UV-A: 0.999, reflected global/UV-A: 0.983). Especially during the beginning of the events - when the concentrations of the smallest detectable particles are less than 1000 particles $\mathrm{cm}^{-3}$ - the values are 
Table 1. Continued...

\begin{tabular}{|c|c|c|c|c|c|c|c|c|c|c|c|c|c|}
\hline & Event Days & & & Event & & UV-A & Global & $\mathrm{H}_{2} \mathrm{O}^{(*)}$ & & $\mathrm{SO}_{2}$ & $\mathrm{NO}_{x}$ & hor.Std & ver.Std \\
\hline (yymmdd) & Day & & hrs:min & hrs:min & hrs:min & {$\left[\mathrm{W} \mathrm{m}^{-2}\right]$} & {$\left[\mathrm{W} \mathrm{m}^{-2}\right]$} & {$\left[\mathrm{mol} . \mathrm{cm}^{-3}\right]$} & {$\left[{ }^{\circ} \mathrm{C}\right]$} & [ppb] & [ppb] & {$\left[\mathrm{m} \mathrm{s}^{-1}\right]$} & {$\left[\mathrm{ms}^{-1}\right]$} \\
\hline 990909 & 252 & A & 08:00 & 13:30 & 05:30 & 11.0 & & & 8.8 & & & 2.63 & 0.50 \\
\hline 990910 & 253 & A & $10: 00$ & 13:00 & 03:00 & 21.4 & 392.2 & 2.50 & 12.8 & 0.06 & 0.99 & 6.31 & 1.15 \\
\hline 990911 & 254 & A & 09:10 & $15: 50$ & 06:40 & 19.2 & 379.1 & 2.34 & 10.6 & 0.07 & 0.80 & 2.44 & 0.54 \\
\hline 990914 & 257 & B & 10:10 & $15: 50$ & 05:40 & 23.4 & 471.0 & 1.72 & 6.1 & & 0.71 & 4.65 & 0.83 \\
\hline 990915 & 258 & A & 09:50 & $15: 20$ & 05:30 & 20.2 & 408.4 & 1.74 & 8.1 & & & 2.75 & 0.66 \\
\hline 990916 & 259 & B & 11:00 & 15:00 & 04:00 & 24.4 & 467.1 & 2.00 & 8.9 & 0.26 & 1.00 & 5.20 & 0.82 \\
\hline 990919 & 262 & $\mathrm{C}$ & 13:10 & 16:10 & 03:00 & 25.3 & 467.4 & 2.02 & 12.8 & 0.05 & 1.19 & 3.94 & 0.92 \\
\hline Sept. & Non-events: 21 & & 09:00 & 11:00 & & 14.6 & 260.5 & 3.02 & 11.3 & 0.50 & 2.68 & 3.42 & 0.67 \\
\hline Oct. & Non-events: 28 & & $10: 00$ & $12: 00$ & & 6.8 & 106.9 & 2.16 & 4.8 & 0.17 & 1.75 & 3.66 & 0.56 \\
\hline
\end{tabular}

(*) all $\mathrm{H}_{2} \mathrm{O}$ values have to be multiplied with the factor of $10^{17}$

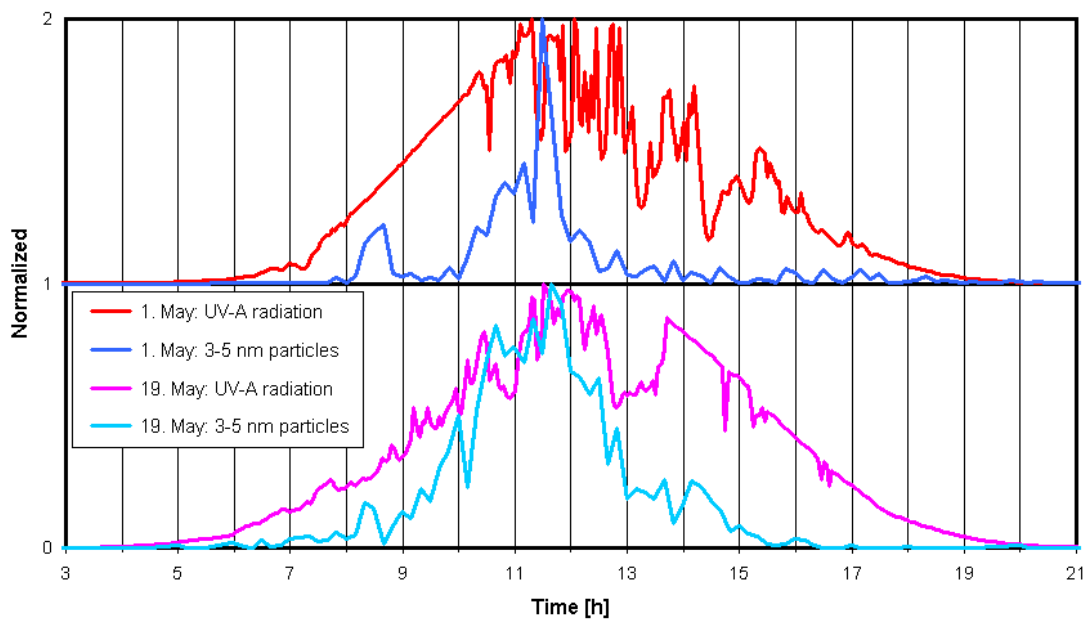

Fig. 4. Normalised values of UV-A solar radiation ( 3 minutes time interval) and the concentration of $3-5 \mathrm{~nm}$ particles (10 minutes time interval).

mostly between 1 and 1.5 in Fig. 3. This means that during these periods the UV-A irradiance exceeds the values of the other wavelength bands between 0 and 33\%. This is a first indication that UV-A is more important than UV-B or any other radiation parameter for the formation of new particles. Theoretical and laboratory work with the photochemical and/or chemical reactions and the absorption cross sections of the participant molecules will be needed to gain information on the influence of the solar spectrum on the formation of new aerosols. At the present stage we use UV-A in the next fig- ure and in the calculations of a "nucleation parameter" in Sect. 3.8 as the best correlated radiation parameter.

An analysis of the UV-A radiation and the 3-5 nm particle profiles on event days showed in many cases a high correlation with the temporal trend of the two graphs. On many event days and also on some days declared as nonevent days, the appearance of the smallest detectable particles seems to be determined by solar irradiance. In the following discussion we use two days in May as examples of this phenomenon. Fig. 4 shows the normalised UV-A solar 

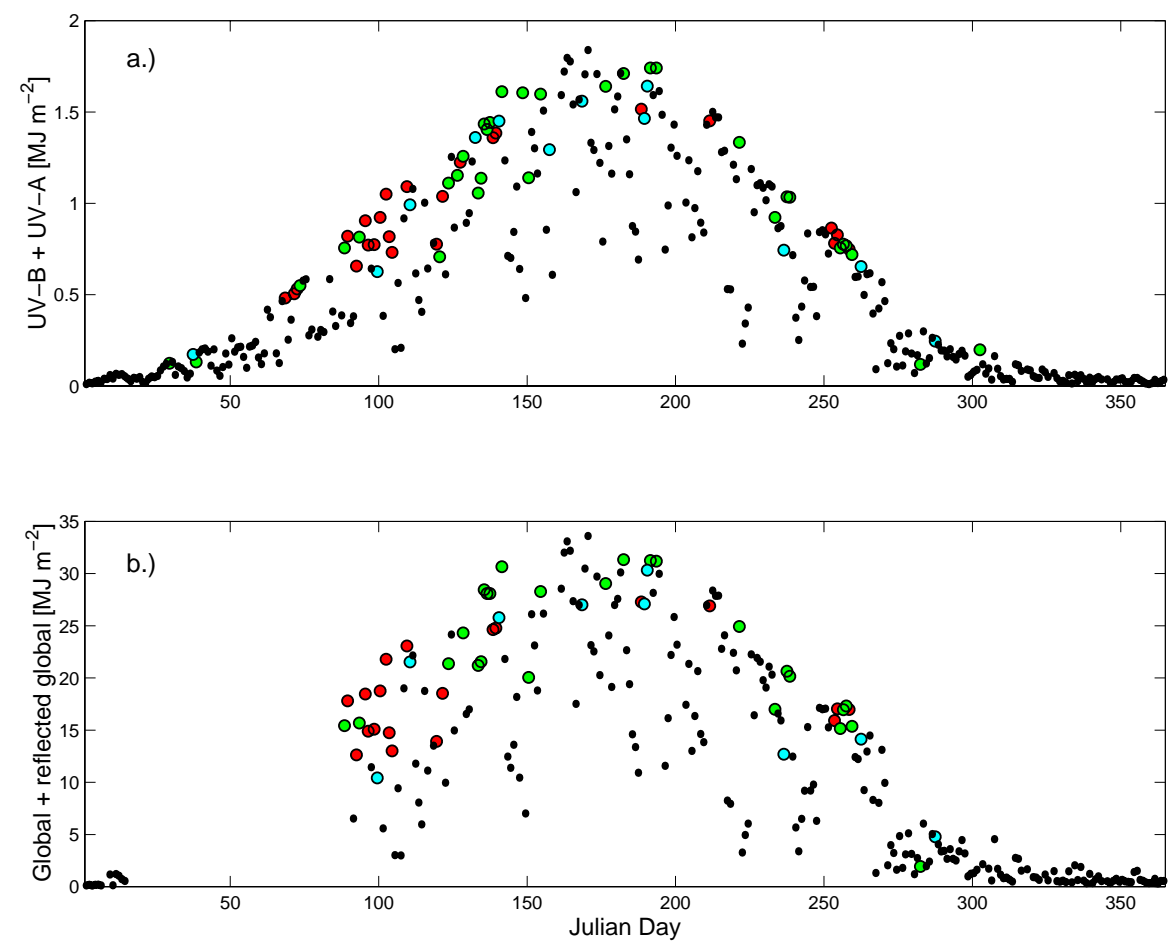

Fig. 5. Daily integrated sum of (a) UVB + UV-A and (b) Global + reflected global solar radiation for the year 1999. A-, B- and C-Events are marked with red, green and cyan labels respectively and the non-event days are marked with black dots. radiation curve with a time resolution of 3 minutes and the normalised $3-5 \mathrm{~nm}$ particle concentration profile with a time resolution of 10 minutes for Julian days 121 and 139 (1 and 19 May, respectively). On 1 May (upper curve) UV-A rises rather continuously until 11.18 a.m., when clouds appear and decrease the UV-A radiation by about $45 \%$. Approximately 10 minutes later the radiation increases again close to the daily maximum, and after that clouds continued to interrupt the solar radiation intensity from time to time during the rest of the day. The concentration of 3-5 nm particles had a maximum on that day at $11.30 \mathrm{a} . \mathrm{m}$. and the concentration decreased more than $95 \%$ during the next half hour. Taking the time resolutions of both measurements into account, the delay between the peak values of the two parameters is $12 \pm$ 7.5 minutes. On this day, there are a couple of more peaks in the concentration of the $3-5 \mathrm{~nm}$ particle concentration profile which seem to appear after UV-A peaks and even higher correlation can be seen on the next example day. On 19 May (Julian day 139), the rising part of the particle curve has 5 dominant peaks before 11.30 a.m. All of them seem to be related to peaks of the UV-A spectrum and the time delay between the corresponding peaks decreases from $37 \pm 7.5$ minutes at around $8 \mathrm{a} . \mathrm{m}$. to $9 \pm 7.5$ minutes at $11.35 \mathrm{a} . \mathrm{m}$. After that, clouds cover the sun for about 2 hours and the concentration of the smallest detectable particles decreases from more than 1000 particles $\mathrm{cm}^{-3}$ down to 180 particles $\mathrm{cm}^{-3}$. The sky clears at 2.10 p.m., after which the particle concentration rises to 260 particles $\mathrm{cm}^{-3}$. In these cases and on many other days during the year, the times between sev- eral related peaks of the two parameters lie in the range from some minutes to about half an hour with the shortest time delays measured around solar noon. One possible explanation for small time delays around solar noon may be the intensive solar radiation, which may initiate one or more photochemical reactions producing condensable vapours.

Throughout the year, nucleation occurs only if solar radiation is unimpeded by clouds for a couple of hours. There are still many days in 1999, however, with relatively high amounts of solar radiation and no detectable particles. The diurnal integrated sum of UV-A and UV-B and the sum of global and reflected global solar radiation measured above the forest are shown in Figs. 5a and b for the year 1999. Because of instrumentation problems there are no measurements available for reflected global solar radiation between Julian days 15 and 88 . The annual average of integrated solar irradiance is $53.3 \%$ higher for UV and 54.2\% higher for the sum of global and reflected global radiation on event days than on non-event days. The amount of integrated solar radiation on event days shows large differences during the year. The lowest value for UV is $0.11 \mathrm{MJ} \mathrm{m}^{-2}$ on 9 October and the highest value is $1.74 \mathrm{MJ} \mathrm{m}^{-2}$ on $12 \mathrm{July}$. For the sum of global and reflected global radiation the lowest value is $1.94 \mathrm{MJ} \mathrm{m}^{-2}$ on 9 October and the highest value is $31.33 \mathrm{MJ} \mathrm{m}^{-2}$ on $1 \mathrm{July}$. The amount of solar irradiance exhibits a large variation in 1999 on event days and it seems that there are periods throughout the year, when the influence of solar radiation on the new aerosol formation is more pronounced than during other periods. From March until May, 


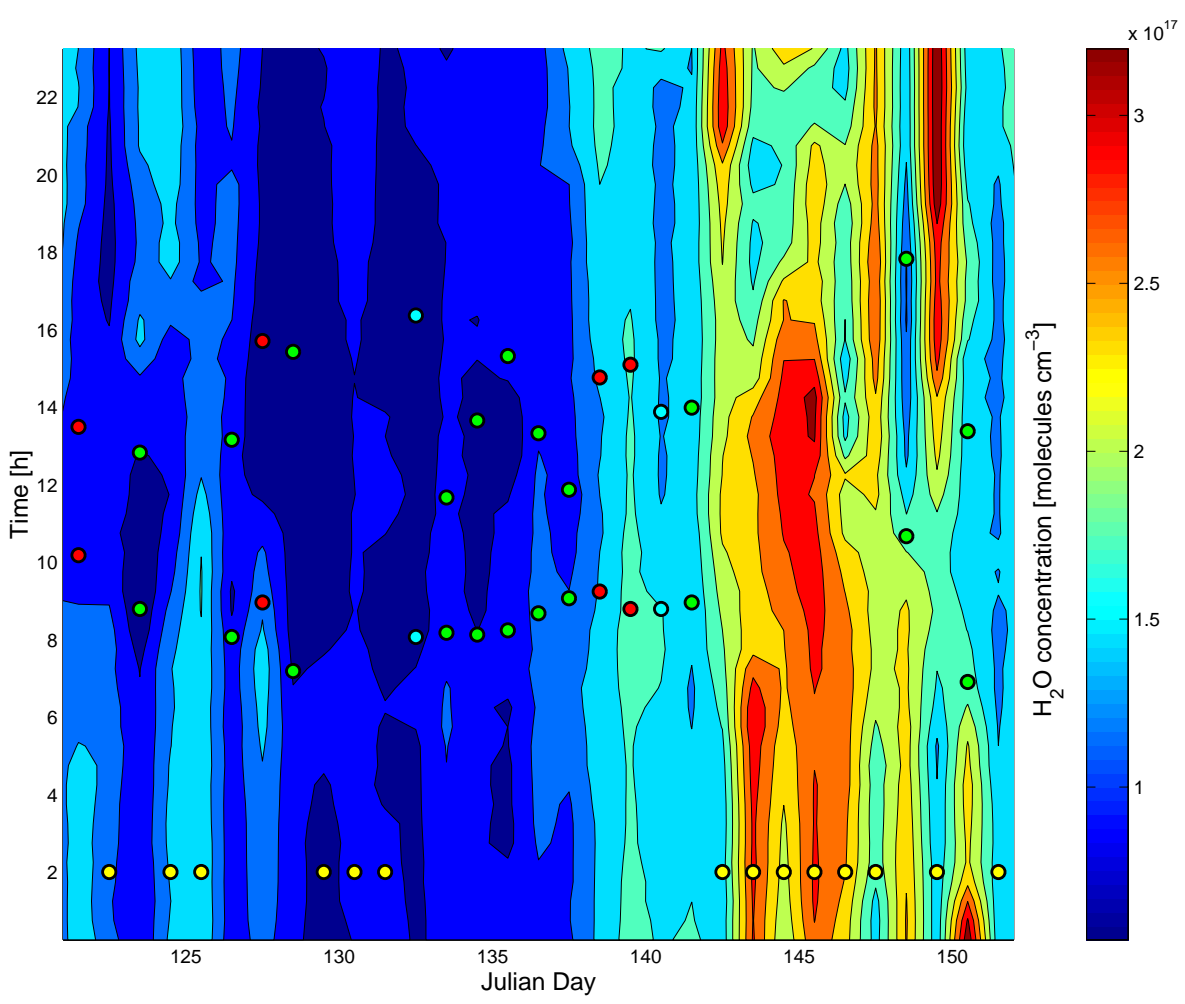

Fig. 6. Half-hour average values of $\mathrm{H}_{2} \mathrm{O}$-concentration at $67 \mathrm{~m}$ during May 1999. The initiation and the cut-off of the smallest detectable particle bursts are marked with red, green and cyan labels for A-, B- and C-Events respectively; yellow labels are used for non-event days.

when more than $50 \%$ of all events took place, as well as in August and September, the integrated values of UV and global radiation on event days are mostly higher than the average values during the corresponding month. There are only a few event days with relatively small values like for example Julian day 150 (green mark in Figs. 5a and b). On this day, solar radiation increased quite sharply until cloud cover appeared around $10 \mathrm{a} . \mathrm{m}$. The concentration of the smallest detectable particles increased around 7 a.m. (nucleation start), decreased with the appearance of the clouds and then started to fluctuate in pace with the appearance and disappearance of clouds. Similar behaviour can be seen in other event days with UV or global radiation values smaller than the average. In June and July only 10 days with continuous, significant particle formation were measured, although solar radiation reaches the highest values of the year. During this period other parameters might limit the nucleation, as many nonevent days show a perfect sinusoidal UV profile with high values of UV and global irradiance.

High amounts of solar radiation during nucleation events as well as the high conformity between the daily curves of UV-A solar radiation and the concentration of 3-5 $\mathrm{nm}$ particles on many event days lead us to believe that radiation is an important parameter for the formation of new particles.

\section{$3.2 \mathrm{H}_{2} \mathrm{O}$-concentration}

The half-hour average concentration of $\mathrm{H}_{2} \mathrm{O}$ measured at $67 \mathrm{~m}$ is given in Fig. 6 for May 1999. The average diurnal profile of $\mathrm{H}_{2} \mathrm{O}$ for May shows values between $1.3 \times 10^{17}$ and $1.4 \times 10^{17}$ molecules $\mathrm{cm}^{-3}$ in the morning and a minimum of $1.07 \times 10^{17}$ molecules $\mathrm{cm}^{-3}$ at noon on event days and values between $1.6 \times 10^{17}$ and $1.8 \times 10^{17}$ molecules $\mathrm{cm}^{-3}$ during the non-event days. During the night and in the morning the concentrations of $\mathrm{H}_{2} \mathrm{O}$ are very low on most event days compared to the average values of the corresponding month (see Fig. 6: first half of May). However, sometimes it decreases before the particle burst starts and the formation of new particles is low until the amount of water molecules has decreased sufficiently even though the solar radiation is high (compare Julian day 121 or 148 in Figs. 2 and 6). The reasons for the decrease in $\mathrm{H}_{2} \mathrm{O}$-concentration during the day could be the enhanced vertical transport mechanism due to high values of solar radiation. The low concentration of $\mathrm{H}_{2} \mathrm{O}$ molecules during the morning or at the beginning of the event start - compared to the average value of the corresponding month - is highly correlated with event days of the year.

Figure 7 shows the average concentration of $\mathrm{H}_{2} \mathrm{O}$ between 9 and 11 a.m. for the whole year. Throughout the year the amount of water molecules is lower on days with new particle formation compared to the non-event days of the corre- 

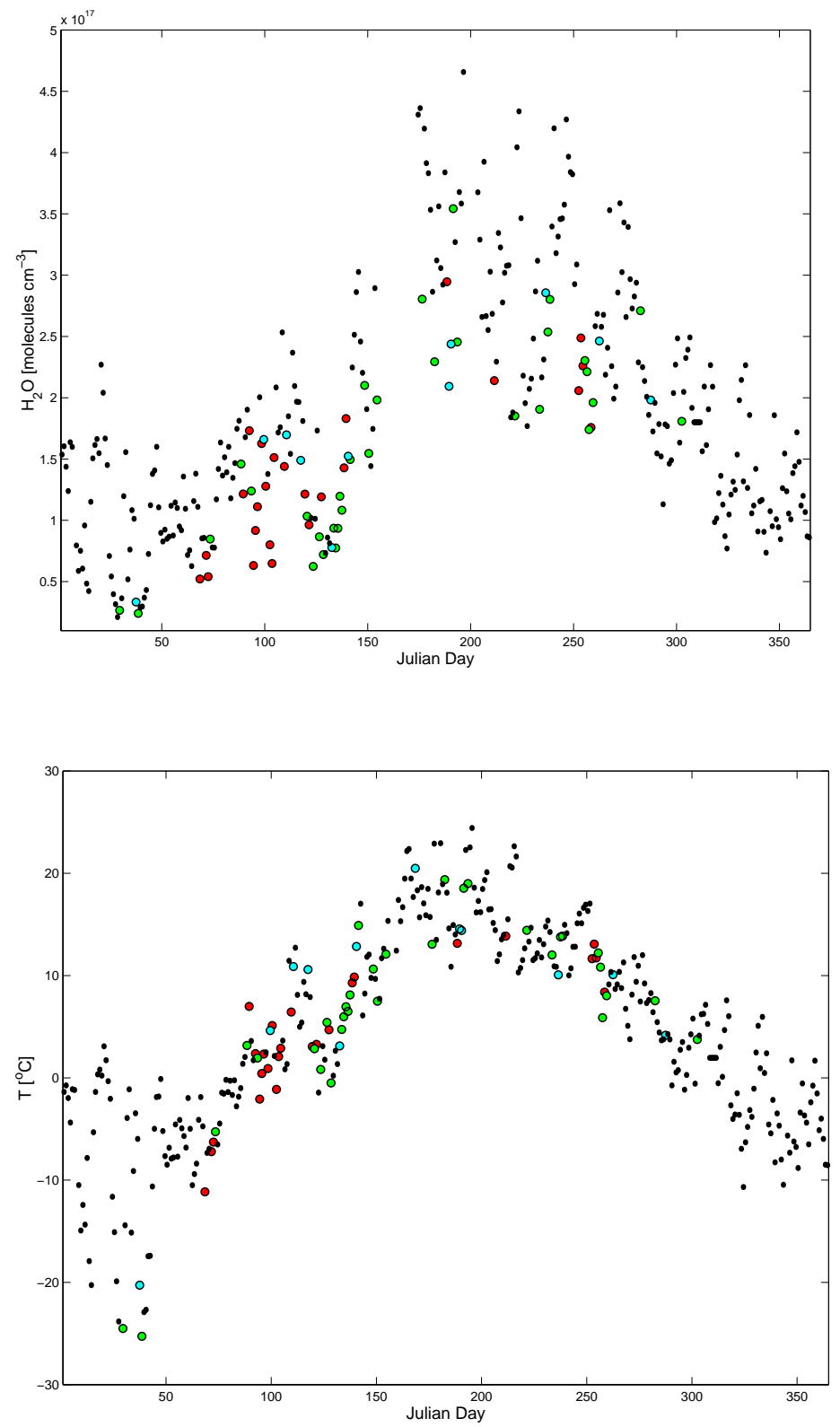

Fig. 7. Average values during the morning (9 to 11 a.m.) for the concentration of $\mathrm{H}_{2} \mathrm{O}$ at $67 \mathrm{~m}$ for the year 1999 . A-, B- and C-Events are marked with red, green and cyan labels respectively and the non-event days are marked with black dots.
Fig. 8. Average value during the morning (9 to 11 a.m.) for the temperature at $67 \mathrm{~m}$ for the year 1999. A-, B- and CEvents are marked with red, green and cyan labels respectively and the nonevent days are marked with black dots. sponding month. This relatively low concentration of $\mathrm{H}_{2} \mathrm{O}$ during the night, in the morning or a short time before the event starts seems like a meteorological condition for the formation of new aerosols. From Figs. 5 and 7 we conclude that the combination of both parameters - solar radiation and concentration of $\mathrm{H}_{2} \mathrm{O}$ - could be an important key for the formation of new aerosols. In June and July many days with high solar irradiance did not show significant particle formation, and the concentration of water molecules reached the highest values of the year during these days. For example, on 28 June the sum of integrated global and reflected global solar radiation is $26.9 \mathrm{MJ} \mathrm{m}^{-2}$ with a weakly interrupted sinusoidal profile. The average concentration of $\mathrm{H}_{2} \mathrm{O}$ between 9 and $11 \mathrm{a} . \mathrm{m}$. is $3.88 \times 10^{17}$ molecules $\mathrm{cm}^{-3}$, increasing during the day up to $4.18 \times 10^{17}$ molecules $\mathrm{cm}^{-3}$ at $6 \mathrm{p} . \mathrm{m}$. The concentration of $3-5 \mathrm{~nm}$ particles is less than 20 particles $\mathrm{cm}^{-3}$ and the total particle concentration is less than 2000 particles $\mathrm{cm}^{-3}$ during the day. While there is no proof that high amounts of water molecules are responsible for preventing the formation of new aerosols, there are many days like 28 July. These days show sinusoidal radiation profiles with low number concentration of existing particles and relatively high amounts of water molecules, but no formation of new aerosols. The physical or chemical explanation as to why the concentration of $\mathrm{H}_{2} \mathrm{O}$ may affect the formation of new particles is still unclear. At the present stage of research 


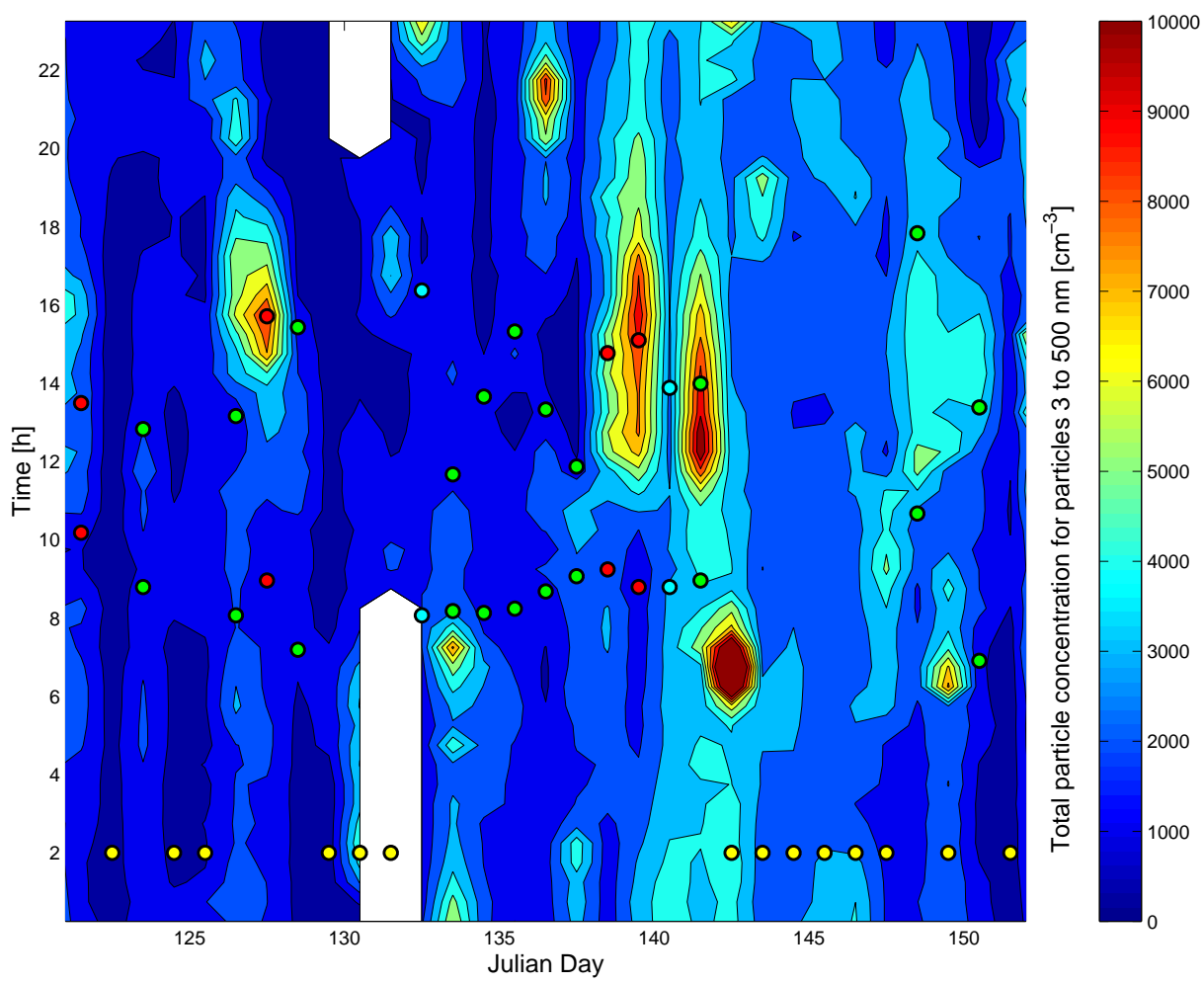

Fig. 9. Half-hour average values of total particle number concentrations for particles between 3 and 500 nm during May 1999. The initiation and the cut-off of the smallest detectable particle bursts are marked with red, green and cyan labels for A-, B- and C-Events respectively; yellow labels are used for non-event days.

there are still too many open questions about the responsible condensable vapours and the photochemical and/or chemical reactions with the precursor gases leading to the condensable vapours to formulate a plausible hypothesis about the effects of $\mathrm{H}_{2} \mathrm{O}$ concentration on the formation of new particles.

By analysing all days throughout the year it appears that the amount of available water molecules, just like radiation seems to play an important role in the formation of new particles.

\subsection{Temperature}

The average temperatures between 9 a.m. and 11 a.m. for the year 1999 are given in Fig. 8. There is a very light trend for the event day temperatures to be lower than the non-event day temperatures and especially during winter when nucleation days show temperatures much below the average values for these months (see also Table 1). For example the nucleation events on 29 January and on 7 February have temperatures below $20^{\circ} \mathrm{C}$. In spring this tendency decreases and during summer and autumn the temperature differences between event and non-event days are still smaller. Low temperatures may be important during winter and to some extend in spring when solar radiation is still weak and enhance the formation of new aerosols at that time of the year, but in late spring, summer and autumn, temperature plays a subordinate role in the nucleation.

\subsection{Total particle number concentration}

The next parameter we will discuss is the total particle number concentration measured for particles between 3 to $500 \mathrm{~nm}$. High values of the existing particle concentration influence the formation of new aerosols in two ways; the undetectable particles smaller than $3 \mathrm{~nm}$ (Thermodynamic stable clusters - TSCs) will coagulate with the larger particles and the available condensable vapours (such as organics, inorganic acids and ammonia) will condense to the existing particles. This can be seen on Julian day 142 (Fig. 9), when polluted air came from south. Total particle concentration (up to 20000 particles $\mathrm{cm}^{-3}$ ) may prevent the formation of new aerosols, although all the other parameters (radiation, $\mathrm{H}_{2} \mathrm{O}$ concentration and temperature) would be expected to favour nucleation. On this day, there was an increase in the concentration of the $3-5 \mathrm{~nm}$ particles from 0 up to 150 particles $\mathrm{cm}^{-3}$ after the polluted air passed at around 10 a.m. This leads to the possibility that high amounts of newly formed particles might be produced, but the high values of existing particles (between 3000 and 5000 particles $\mathrm{cm}^{-3}$ ) during the rest of the day may prevent it. Coupled mechanisms (inter- 

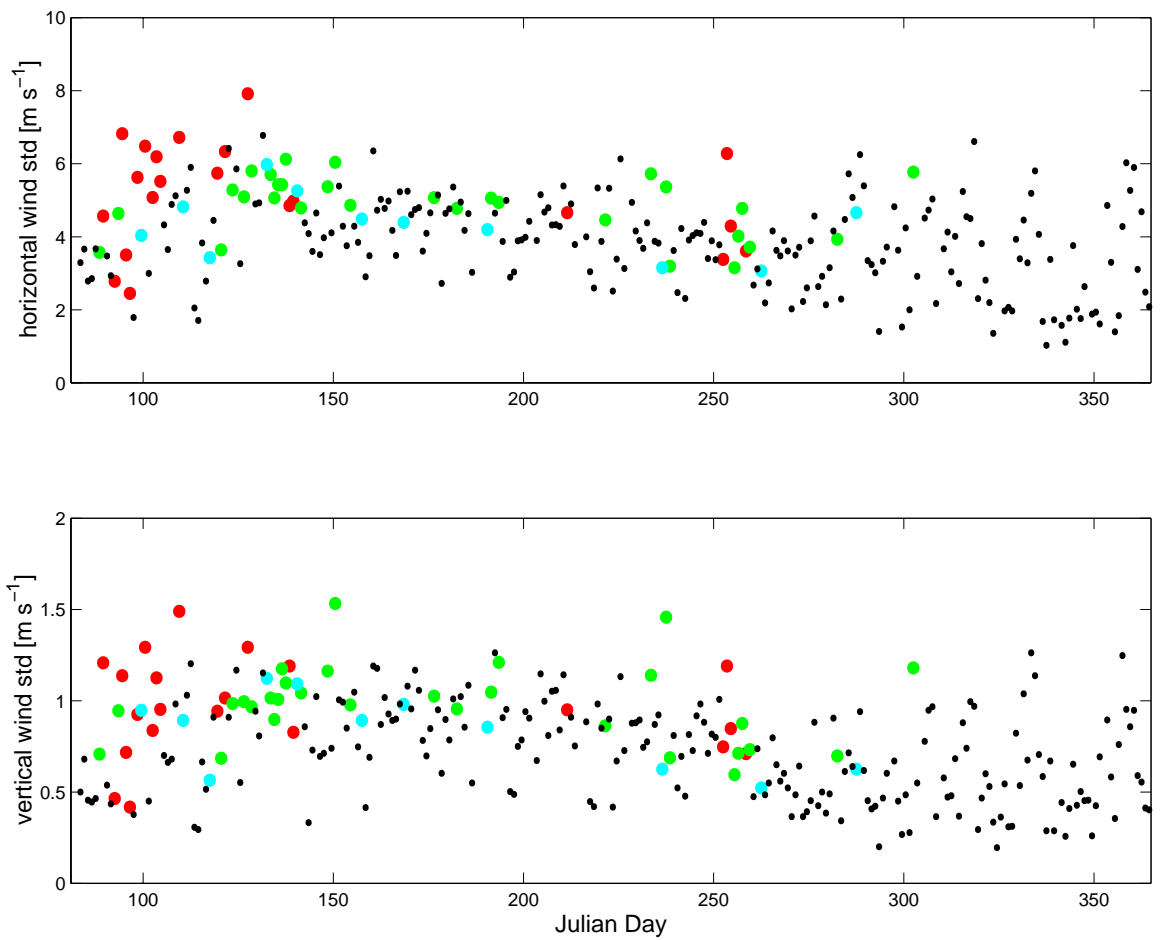

Fig. 10. Average value during the morning (9 to 11 a.m.) for the horizontal and vertical wind standard deviations measured at $100 \mathrm{~m}$ for the year 1999. A-, B- and C-Events are marked with red, green and cyan labels respectively and the non-event days are marked with black dots. ruption of solar radiation by clouds and polluted air masses) may have stopped the production of new aerosols between Julian days 129 and 131 .

\subsection{Boundary layer influence}

It is still somehow unclear, if the formation of the smallest detectable particles occurs in the surface layer or in the mixed boundary layer. Buzorius et al. (2001) note that during the BIOFOR campaign the dominant particle flux direction for particles larger than $10 \mathrm{~nm}$ was downward on event days. Nilsson et al. (2001a) suggest for the same periods that there is a connection between boundary layer dynamics and the formation of the new aerosols. Analysis between 17 March till the end of December of 1999 of vertical wind data and vertical and horizontal wind standard deviations, which are proportional to the vertical and horizontal turbulent kinetic energies (TKE) shows the vertical wind-direction to be very often downward before the new particle bursts. This is followed by downward and upward wind-direction during the event. There are some event days with continuously upward wind-direction and high numbers of newly formed particles. For example on Julian day 89 (30 March) the average upward vertical wind during the time of the particle burst is $0.29 \mathrm{~m} \mathrm{~s}^{-1}$ with a minimum of $0.1 \mathrm{~m} \mathrm{~s}^{-1}$ and a maximum of $0.8 \mathrm{~m} \mathrm{~s}^{-1}$ and the maximum number concentration of the $3-5 \mathrm{~nm}$ particles between $11 \mathrm{a} . \mathrm{m}$. and $11.30 \mathrm{a}$.m. is 2000 particles $\mathrm{cm}^{-3}$.

The average values of the horizontal and vertical wind standard deviations between 9 and 11 a.m. measured at $100 \mathrm{~m}$ are shown in Fig. 10. These parameters indicate, beside some high values in spring on nucleation days (for example Julian day 109 vertical wind standard deviation is $1.78 \mathrm{~m} \mathrm{~s}^{-1}$ ), no significant differences between days with or without an event. The mean value for the vertical wind standard deviation is about $0.9 \mathrm{~m} \mathrm{~s}^{-1}$ through spring and summer and about $0.7 \mathrm{~m} \mathrm{~s}^{-1}$ in autumn. The theory of Nilsson et al. (2001a) is based on data from the BIOFOR campaigns (including spring 99). During this time there are some indications that the turbulent kinetic energy is higher on event days than on nonevent days indicating a connection between the boundary layer dynamics and the formation of new aerosols. Later on during the year, the average morning values of the horizontal and vertical wind standard deviations do not show significant correlation with particle formation. It is still possible that the importance of different parameters affecting nucleation varies throughout the year, as seemed to be the case with the parameters considered above. But regarding the results for the whole year it becomes clear that nucleation is not generally related to high amounts of measured turbulent kinetic energy or to vertical wind-direction. This could be due to the fact that the sodar instrument and the DMPS system are approximately $200 \mathrm{~m}$ apart from each other and that convective plumes may have diameters much smaller than this. To get a definitive answer on this question it would be necessary to measure the particle concentrations and the boundary layer behaviour at the same location. Further vertical aerosol distributions throughout the whole boundary layer during event 

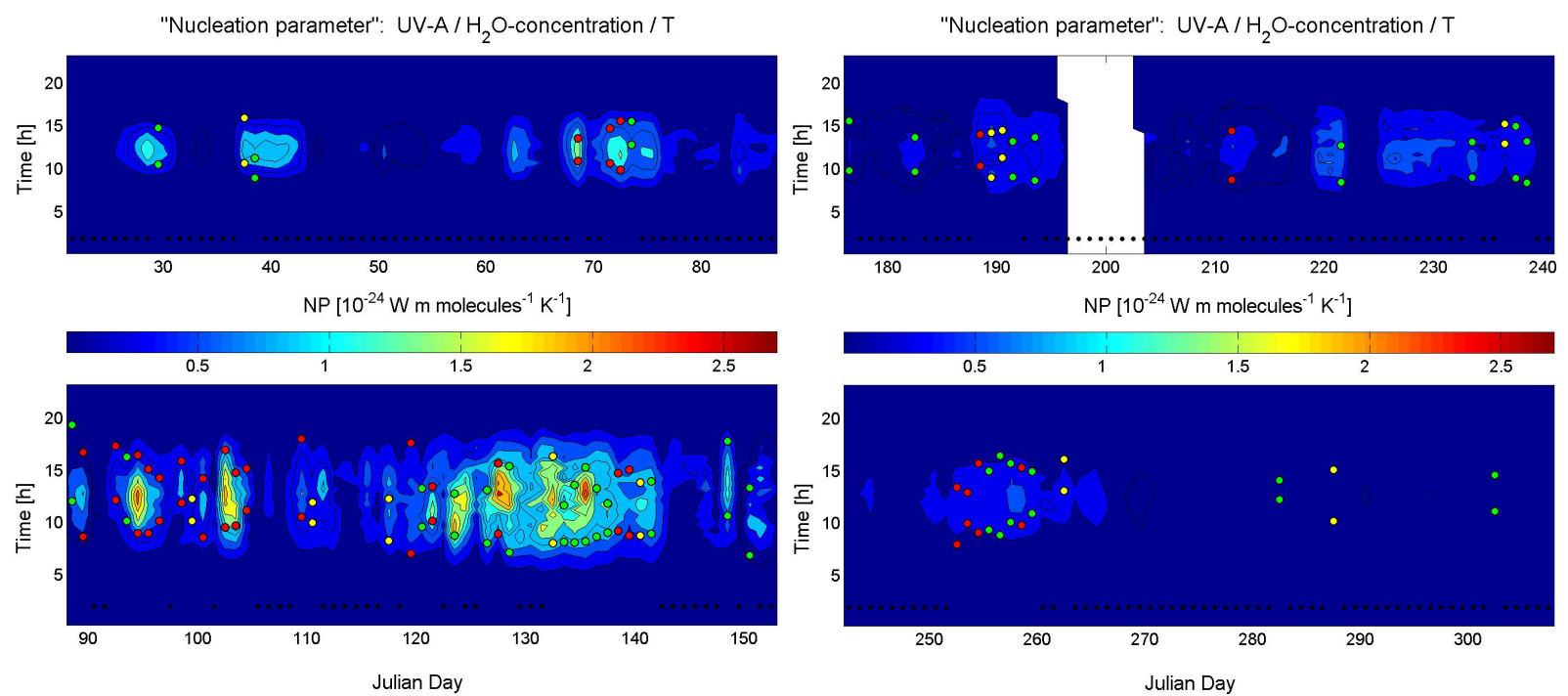

Fig. 11. Half hour average values of the "nucleation parameter" for the year 1999 (1-20 January and 4 November until the end of the year are left out because all values are smaller than $10 \%$ of the yearly maximum and nucleation did not occur during that time; between $3-25$ June and 15-22 July no data of $\mathrm{H}_{2} \mathrm{O}$ were measured). The initiation and the cut-off of the $3 \mathrm{~nm}$ particle bursts are marked with red, green and cyan labels for A-, B- and C-Events respectively; yellow labels are used for non-event days.

and non-event days would give important information on the origin of the smallest detectable particles.

\section{6 $\mathrm{NO}_{\mathrm{x}}$ and $\mathrm{SO}_{2}$ concentrations}

The concentrations of $\mathrm{NO}_{\mathrm{x}}$ and $\mathrm{SO}_{2}$ were analysed for the whole year. The average values between 8 and $12 \mathrm{a} . \mathrm{m}$. for the two gases lie between 2 and 3 ppb or 0 and 1 ppb, respectively and show smaller variations during the summer. In most cases, high peaks of these gases (consequently polluted air) are correlated with high numbers of total particle concentrations. There is a trend that low concentrations of $\mathrm{NO}_{x}$ in the morning are measured during event days, but this is not the rule and often new particles appear even when the concentration of this gas is higher than the average. In the case of $\mathrm{SO}_{2}$ no significant differences were found between event and non-event days.

\subsection{Horizontal wind-speed and the wind-direction}

There is no correlation between the horizontal wind-speed and the formation of aerosols. Wind-direction seems to be an important parameter because of pollution from the westsouth-west (station building and city of Tampere). Otherwise, it is more important which trajectory the air mass followed before reaching Southern Finland (Nilsson et al., 2001b).

\section{8 "Nucleation parameter"}

Both the concentration of water molecules and solar radiation correlate strongly with the appearance of new particles as we saw in Sects. 3.1 and 3.2. Both parameters seem to be keys to causing nucleation. There are still days with low values of $\mathrm{H}_{2} \mathrm{O}$-concentration and high solar radiation but no nucleation (e.g. Julian days 124 or 129 to 131). Nilsson et al. (2001b) proposed that during the BIOFOR campaigns (spring 1998, 1999 and autumn 1998) nucleation occurred in Arctic and to some extent in Polar air masses, with a preference for air in transition from marine to continental air masses, but never in Tropic air masses. Arctic and Polar air masses that arrive in Finland from the Northwest to the Northeast have lower temperatures than other air masses. By analysing temperature profiles for the whole year (see Sect. 3.3), we saw that on most event days in winter and early spring the temperature during the morning is lower than the average temperature of the corresponding month. Taking these three results into account, we developed a "nucleation parameter" (NP) for the year 1999 (Figs. 11a and b; the days 1-20 January and 4 November until the end of the year are left out because all values are smaller than $10 \%$ of the yearly maximum and nucleation did not occur during that time; between 3-25 June and 15-22 July $\mathrm{H}_{2} \mathrm{O}$ concentrations were not measured). The values were calculated by

$$
N P=U V-A /\left[c\left(\mathrm{H}_{2} \mathrm{O}\right) T\right]
$$

Here, $U V-A$ is the $\mathrm{UV}-\mathrm{A}$ radiation flux, $c\left(\mathrm{H}_{2} \mathrm{O}\right)$ is the water number density, and $T$ is the temperature. The maximum value of the whole year was on Julian day 135 at 12.45 with $2.678 \times 10^{-24} \mathrm{~W}$ m molecules ${ }^{-1} \mathrm{~K}^{-1}$.

In April and May the formation of new particles starts only when the "nucleation parameter" reaches values of at least $2.7 \times 10^{-25} \mathrm{~W}$ m molecules ${ }^{-1} \mathrm{~K}^{-1}$, which means that at this 
time the "nucleation parameter" reaches $10 \%$ of its yearly maximum. On these days the maximum value of the parameter always exceeds $8 \times 10^{-25} \mathrm{~W} \mathrm{~m}$ molecules ${ }^{-1} \mathrm{~K}^{-1}$. Not all days with high values of this parameter, however, lead to the formation of new aerosols. There are several occasions over the year when high values of the "nucleation parameter" (greater $5.4 \times 10^{-25} \mathrm{~W} \mathrm{~m}$ molecules ${ }^{-1} \mathrm{~K}^{-1}$ ) were found and no nucleation was observed. The following is a detailed discussion about these days or periods.

- Julian days 26 - 30: All days show at least some newly formed small particles $\left(>200 \mathrm{~cm}^{-3}\right)$ and the total particle concentration rises by factors of 3 to 10 depending on the day. There were good meteorological conditions during these days for particle production, but the high amounts of existing particles (especially on Julian day 28: 3000 to 8000 particles $\mathrm{cm}^{-3}$ ) and enhanced concentrations of $\mathrm{NO}_{x}$ between Julian days 26 to 28 may have limited the formation of new aerosols during these days. On Julian day 30 the wind-direction changed around 10 a.m. to south and the temperature increased by more than $11 \mathrm{~K}$ from 8 a.m. to noon.

- Julian days 39 - 42: After Julian days 37 and 38 (event days) polluted air with total particle concentrations up to 10000 particles $\mathrm{cm}^{-3}$ (Julian day 41) mainly from east to south-south-west prevented nucleation during this period.

- Julian day 50: Air mass with total particle concentrations up to 5000 particles $\mathrm{cm}^{-3}$ arrived from southeast.

- Julian days 62 -64: On these days all parameters indicated favourable conditions for nucleation: relative high solar radiation, low concentrations of $\mathrm{H}_{2} \mathrm{O}$, low temperature and unpolluted air. However, compared to the days in March when nucleation occurred the solar radiation was more than $15 \%$ lower. It might be that calculating the "nucleation parameter" requires a more complex equation incorporating a monthly or seasonal distribution for each parameter.

- Julian days 74 and 75: Both days show high amounts of existing particles $\left(>4000\right.$ particles $\mathrm{cm}^{-3}$ ).

- Julian day 83: Polluted air mass with total particle concentration rising from 300 to 4000 particles $\mathrm{cm}^{-3}$ arrived from southwest after 8 a.m.

- Julian day 111: In the beginning of April the formation of new aerosols occurred on all days with high values of the "nucleation parameter". On 20 April (Julian day 110) around noon polluted air with total particle concentration larger than 5000 particles $\mathrm{cm}^{-3}$ arrived from south and may have prevented the formation of new particles on that day and the next two days under the same conditions.
- Julian day 115: In the morning, a polluted air mass from the southwest with total particle concentration greater than 4000 particles $\mathrm{cm}^{-3}$ moved over the station and may have provided the formation of new particles during that day.

- Julian day 181: Very good conditions for nucleation considering the incoming solar radiation, but the concentration of water molecules was very high during the night $\left(>4.3 \times 10^{17}\right.$ molecules $\mathrm{cm}^{-3}$ - dropped down to $2.8 \times 10^{17}$ molecules $\mathrm{cm}^{-3}$ until noon) and the total particle number concentration varied between 1000 and 2000 particles $\mathrm{cm}^{-3}$. One of these parameters or the combination of the two may be the reason why nucleation did not happened on this day.

- Julian day 192: The wind blew from southwest during the night and until noon, and the particle number concentration increased to more than 3000 particles $\mathrm{cm}^{-3}$.

- Julian days 212 - 216: Throughout these days 'random' formation of $3-5 \mathrm{~nm}$ particles that sometimes grew to larger particles were measured. Formation of new aerosols often happened but some condition(s) needed for these particles to grow to the Aitken mode were missing. Also at this time problems in the DMPS system concerning measurement of the smallest particles started and on some days it was difficult to decide what signals are real.

- Julian days 219 and 220: The same pattern as on Julian days $212-216$ can be seen on these days and there were a lot of clouds interrupting the solar radiation especially on Julian day 220.

- Julian days 226 - 228: DMPS system was not running during this time.

- Julian days 229 to 231: Many clouds interrupt the solar irradiance preventing the occurrence of nucleation events.

The analysis of the non-event days with relatively high values of the calculated "nucleation parameter" reveal that in many cases large amounts of existing particles mostly transported from a southeast-southwest direction to the station might be the reason for no nucleation. Out of this reason the concentration of the existing particles and their size distribution should be included into the calculation of NP values. However a simple division of the NP values with the particle surface area did not improve the distribution of the nucleation parameters on event and non-event days. So for future calculations of an improved nucleation parameter a more complex equation has to be invented to incorporate the number concentrations of the existing particles. Besides pollution, clouds interrupting the solar irradiance might limit or on some days even prevent the photochemistry producing condensable vapours. The simple "nucleation parameter" 
used here correlates well with the first half of the year 1999 and the appearance of newly formed particles. Almost all days in this period with values larger than $5.4 \times 10^{-24} \mathrm{~W} \mathrm{~m}$ molecules ${ }^{-1} \mathrm{~K}^{-1}$ and relatively small concentrations of existing particles led to the formation of new aerosols. In the second half of the year, values of the "nucleation parameter" are always very small although 25 event days were measured. The linear equation leading to the "nucleation parameter" currently used is inadequate. Future modifications of this equation should include parameters to adjust for the concentration of undetermined vapours and the number concentration and size of the existing particles. Furthermore, it appears that the relative contributions of the different parameters to nucleation vary according to seasons, indicating that seasonal weighting factors may have to be added.

\section{Summary and conclusions}

It has been showed that the appearance of newly formed 3-5 nm detectable particles is correlated with solar radiation, especially UV-A solar radiation. The formation of new aerosols is always connected with relatively high amounts of irradiance compared to the average of the corresponding month. High amounts of solar irradiance, however, do not automatically lead to an event day. During spring, autumn and winter the high absolute values of solar radiation and an almost cloud-free undisturbed sinusoidal UV-A profile seem necessary for the formation of particles. During summer other parameters may be more important than solar radiation. The concentration of $\mathrm{H}_{2} \mathrm{O}$ may be an important parameter. During the months of June and July with many cloudless days and high solar irradiance, the high concentrations of $\mathrm{H}_{2} \mathrm{O}$ (values greater than $2 \times 10^{17}$ molecules $\mathrm{cm}^{-3}$ ) might prevent nucleation. Throughout the year the concentration of $\mathrm{H}_{2} \mathrm{O}$ on event days is relatively low compared to the average value of the corresponding month or decreases in the beginning of the event. Another parameter, which seems to be important, is the existing total particle concentration. We found that on many days with perfect meteorological conditions (high UV-A irradiance, low $\mathrm{H}_{2} \mathrm{O}$ concentrations and low temperature) a high concentration of existing particles may prevent the formation of new aerosols. In Hyytiälä, this situation arises on days with winds from the southwest, bringing air pollution from Tampere or from the station building. The dilution of the total particle concentration (see Fig. 1) on half of the event days throughout the year before the nucleation starts, could be the result of a vertical transport mechanism (Nilsson et. al., 2001a). It appears that the decrease of the particle concentration (e.g. the cleaning of the air) enables or enhances the production of new aerosols. So in these cases the mixing of relatively clean air from the residual layer with more polluted air from the surface layer in the morning after sunrise could be an important factor for the formation of new aerosols.
Where in the atmosphere nucleation takes place is still an open question. Kulmala et al. (2000a) state that under typical tropospheric conditions, thermodynamic stable clusters with sufficient nucleation rates are produced everywhere in the atmosphere. The short delay times (minutes) on many event days between changes in the UV-A solar radiation profiles and the concentration of newly formed particles (see Fig. 4) could be an indication, that the growth of TSCs to detectable $3 \mathrm{~nm}$ particles happens near the ground in the surface layer and not only in the mixed layer above the forest. If this idea is correct then the existence of precursor vapours with absorption cross sections having peaks in the UV range would explain the high conformity. In this context Kulmala et al. (2000b) found an up to 100 times larger concentration of salts of dimethylamine (DiMA) in the particle phase during event days compared to non-event days in the analysis of impactor data taken during BIOFOR. It is unclear what photochemical reactions are responsible for DiMA transformation into the particulate phase on event days. To obtain more information about the importance of solar irradiance and whether UV-A enhances photochemical reactions necessary for the formation of condensable vapours, spectral irradiance data have to be analysed. If a wavelength depended relation between the formation of new aerosols and UV-A solar radiation exists then this would help to understand these as yet unidentified reactions better.

High correlation between the "nucleation parameter" and the formation of new aerosols especially in the first half of the year 99 has been shown (Figs. 11a and b). In the second half of the year (Figs. 11c and d), however, we still measured 25 event days when the calculated values seem to be too small. The linear definition of the "nucleation parameter" might be too simplified. Seasonal factors for each of the three parameters, concentration of unknown precursor gases and the concentration of the existing particles and their size distribution are factors to be incorporated into an improved "nucleation parameter". We strongly suggest that an equation capable of predicting the appearance of newly formed aerosols and their number concentrations - if it exists at all - use UV-A solar irradiance, the concentration of water molecules, temperature and the existing particle concentration and size distribution.

The results of this paper agree in many points with the results of Clement et al. (2001). They suggest that Finnish forest nucleation is very unlikely at low radiation levels (< $100 \mathrm{~W} \mathrm{~m}^{-2}$ ), which is in full agreement with our results. Furthermore they calculated the ratios of global solar radiation intensity Irad and the removal rate RA of the condensable vapour (RA as a function of the existing and nucleated aerosols, temperature and the vapour-dependent quantities) and found that the formation of new particles over the Finnish forest is very unlikely at low values of Irad / RA $(<105$ $\mathrm{W} \mathrm{s} \mathrm{m}^{-2}$ ). We showed in Sect. 3.8 in a detailed discussion that most non-event days with high values of the calculated "nucleation parameter" are associated with high amounts of existing particles and concluded that on such days the parti- 
cle concentration could be the limited parameter for the formation of new aerosols. Thus both Clement et al. (2001) and the present work suggest that days with high values of solar radiation and low concentrations of existing particles are necessary for the formation of new aerosols. However, these conditions do not automatically lead to the formation of new particles, and other parameters such as the concentration of $\mathrm{H}_{2} \mathrm{O}$ or the concentration of some yet unidentified precursor vapours may be important on such days.

\section{References}

Birmilli, W. and Wiedensohler, A.: New particle formation in the continental boundary layer: Meteorological and gas phase parameter influence, Geophys. Res. Let., 27, 3325-3328, 2000.

Buzorius, G., Rannik, Ü., Nilsson, D., and Kulmala, M.: Vertical fluxes and micrometeorology during aerosol particle formation events, Tellus B, 53, 394-405, 2001. 2001.

Clement, C. F., Pirjola, L., Dal Maso, M., Mäkelä, J. M., and Kulmala, M.: Analysis of particle formation bursts observed in Finland, J. Aerosol Sci., 32, 217-236, 2001.

Jokinen, V. and Mäkelä, J. M.: Closed-loop arrangement with critical orifice for DMA sheath/excess flow system, J. Aerosol Sci., 28, 643-648, 1997.

Korhonen, P., Kulmala, M., Laaksonen, A., Viisanen, Y., McGraw, R., and Seinfeld, J. H.: Ternary nucleation of $\mathrm{H}_{2} \mathrm{SO}_{4}, \mathrm{NH}_{3}$ and $\mathrm{H}_{2} \mathrm{O}$ in the atmosphere, J. Geophys. Res., 104, 26349-26354, 1999.

Kulmala, M., Toivonen, A., Mäkelä, J. M., and Laaksonen, A.: Analysis of the growth of nucleation mode particles observed in Boreal forest, Tellus 50B, 449-462, 1998.

Kulmala, M., Pirjola, L., and Mäkelä, J. M.: Stable sulphate clusters as a source of new atmospheric particles, Nature, 404, 66-69, 2000a.

Kulmala, M., Hämeri, K., Mäkelä, J. M., Aalto, P. P., Pirjola, L., Väkevä, M., Nilsson, E. D., Koponen, I. K., Buzorius, G., Keronen, P., Rannik, Ü., Laakso, L., Vesala, T., Bigg, K., Seidl, W., Forkel, R., Hoffmann, T., Spanke, J., Janson, R., Shimmo, M., Hansson,H.-C., O’Dowd, C., Becker, E., Paatero, J., Teinilä, K., Hillamo, R., Viisanen, Y., Laaksonen, A., Swietlicki, E., Salm, J., Hari, P., Altimir, N., and Weber, R.: Biogenic aerosol forma- tion in the boreal forest, Boreal Environment Research, 5, 281297, 2000b.

Mäkelä, J. M., Aalto, P., Jokinen, V., Pohja, T., Nissinen, A., Palmroth, S., Markkanen, T., Seitsonen, K., Lihavainen, H., and Kulmala, M.: Observations of ultrafine aerosol particle formation and growth in boreal forest, Geophys. Res. Let., 24, 1219-1222, 1997.

Mäkelä, J. M., Dal Maso, M., Laaksonen, A., Kulmala, M., Pirjola, L., Keronen, P., and Laakso, L.: Characteristics of the aerosol particle formation events observed at a boreal forest site in southern Finland, Boreal Environment Research, 5, 299-313, 2000.

Nilsson, E. D., Rannik, Ü., Kulmala, M., Buzorius, G., and ODowd, C.: Effects of the continental boundary layer evolution, convection, turbulence and entrainment on aeroslo formation, Tellus B, 53, 441-461, 2001a.

Nilsson, E. D., Paatero, J., and Boy, M.: Effects of air masses and synoptic weather on aerosol formation in the continental boundary layer, Tellus B, 53, 462-478, 2001 b.

Pirjola, L.: Effects of the increased UV radiation and biogenic VOC emissions on ultrafine sulphate aerosol formation, J. Aerosol Sci., 30, 355-367, 1999.

Väkevä, M., Hämeri, K., Puhakka, T., Nilsson, E. D., Hohti, H., and Mäkelä, J. M.: Effects of meteorological processes on aerosol particle size distribution in an urban background area, J. Geophys. Res., 105, 9807-9821, 2000.

Vesala, T., Haataja, J., Aalto, P., Altimir, N., Buzorius, G., Garam, E., Hämeri, K., Ilvesniemi, H., Jokinen, V., Keronen P., Lahti T., Markkanen T., Mäkelä J. M., Nikinmaa E., Palmroth S., Palva L., Pohja T., Pumpanen, J., Rannik, Ü., Siivola, E., Ylitalo, H., Hari, P., and Kulmala, M.: Long-term field measurements of atmosphere-surface interactions in boreal forest combining forest ecology, micrometeorology, aerosol physics and atmospheric chemistry, Trends in Heat, Mass \& Momentum Transfer, 4, 17$35,1998$.

Weber, R. J., McMurry, P. H., Mauldin, L., Tanner, D. J., Eisele, F. L., Brechtel, F. J., Kreidenweis, S. M., Kok, G. L., Schillawski, R. D., and Baumgardner, D.: A study of new particle formation and growth involving biogenic trace gas species measured during ACE-1, J. Geophys. Res., 103, 16385-16396, 1998.

Weber, R. J., McMurry, P. H., Mauldin III, R. L., Tanner, D. J., Eisele, F. L., Clarke, A. D., and Kapustin, V. N.: New particle formation in the remote troposphere: A comparison of observations at various sites, Geophys. Res. Lett., 26, 307-310, 1999. 